\title{
Refrigeration unit design and Research on automatic control system for air conditioner
}

\author{
Guoyu Wang ${ }^{1, a}$, Jian Chu ${ }^{2, b}$ \\ ${ }^{1}$ Electrical Department, School of Automation and Electronic Engineering, Tianjin University of \\ Technology and Education, Tianjin, 300222, China \\ ${ }^{2}$ School of Automation and Electronic Engineering, Tianjin University of Technology and Education, \\ Tianjin, 300222, China \\ aemail:wangguoyu9@126.com, bemail:chujian6@126.com
}

Keywords: PLC; refrigeration unit; automatic control

\begin{abstract}
PLC in twentieth Century 60 and along with the development of microelectronics and computer technology, PLC technology has been continuously developing. PLC technical indicators continue to improve, function continuously improved, has been widely used in industrial control system to realize the automation of industrial control. It makes the control system of low energy consumption, high reliability. Using PLC to realize the automatic control in the system of central air conditioner refrigerating units, not only economic, convenient operation and maintenance, convenient adjustment of the cooling capacity and to improve the market competitiveness.
\end{abstract}

\section{Introduction}

With the rapid development of national economy and the improvement of urban and rural people's living standard, the central air conditioning system has been widely used in electric power, machinery, hotels, shopping malls, office buildings and other industrial and civil architecture field. The statistics show that the central air conditioning control system power consumption great tradition, and there is a huge waste of energy. Central air conditioning system exist generally ineffective energy consumption more than 30\% ineffective energy consumption of central air conditioning system, some even as high as $50 \%$ or more. Comfort and energy saving is now people put forward new requirements to the central air conditioning system, in the hope that the energy consumption is lower case maintain indoor appropriate temperature, humidity. Because PLC not only has strong logic operation, timing, counting sequence logic control function and data operation, data processing, data transmission and other functions, in addition to the computer and communication network and other functions. This will not only make the operation simple and low energy consumption energy saving, high reliability, strong anti-interference ability, perfect function, convenient installation, simple programming, easy to repair, adjust the volume of cold.

\section{Refrigeration units working principle}

Refrigeration compressor suction refrigerant gas inhalation (such as R134a) and lubricating oil., the compressor compressing the gas of high temperature and high pressure, the oil and gas separation by the oil and gas separator. Lubricating oil through the oil cooler, and then sent back to the suction cycle use, and high temperature and high pressure gas into the condenser, the condenser after becoming the low-temperature and high-pressure gas. After throttling the gas pressure into the evaporator. The gas in the evaporator absorbs heat to realize refrigeration evaporator environment. Gas evaporation after become low pressure gas is returned to the compressor suction port for a new round of cycle. Adjusting the compression ratio of compressed gas can realize the control of refrigerating capacity. 


\section{The hardware design of the control system}

The control system chooses SIEMENS S7-200 as the control center of the system, it is a small programmable controller, applied to all walks of life, automatic detection, monitoring and control of the various occasions. The powerful function of S7-200 series to enable it to operate independently in, or connected into a network can realize the complex control function. The application range covers the replacement of simple control relay to more complex automatic control. Applications is extremely broad, covering all with automatic detection, automatic control of industrial and civil fields. Therefore, air conditioning refrigeration unit using PLC as the control unit, is the core of the control system. PLC controller and out of the water temperature through the temperature sensor measurements into the controller, memory, and finally to control the frequency of the inverter, to control motor speed, regulating water content, according to the indoor temperature, heat exchange control the speed, to achieve the purpose of energy saving. The control system hardware circuit block diagram as shown in Figure 1.

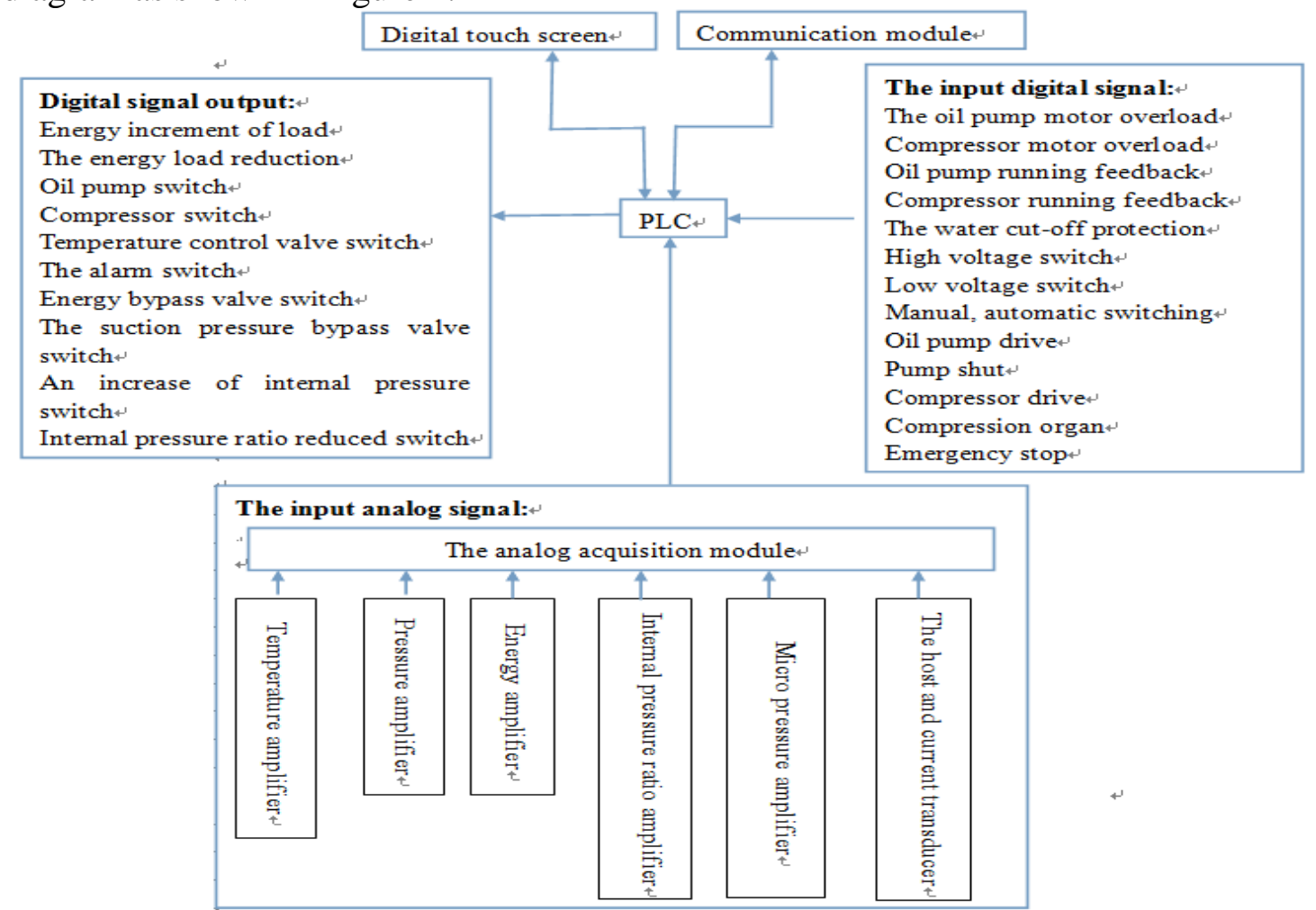

Figure 1: hardware circuit of control system block diagram

\section{The software design of control system}

According to the requirement of control system, in the selected PLC, Using STEP7 Micro/WIN as a process control software development environment. Using PLC ladder diagram language, according to the unit control system requirements to complete the design and debugging of PLC control program. The main function modules include: human-computer interaction, data acquisition, control and regulation, protection alarm, communication etc.. The main work of process control system includes: the initialization procedure: the relevant intermediate register, clear register. The PLC accepts the command signal of the touch screen, the completion of the water temperature cycle refrigeration unit set. The PLC according to the opening number of freezing pump, decided to run state refrigeration unit frequency or frequency. According to the refrigeration cycle water cold water and return water temperature, control of refrigeration unit commitment. Mechanics occurs failure to alarm.

When the PLC is unable to run time, reply original manual way of refrigeration units, ensure the cold water flowing in the refrigeration cycle water, improve the reliability of the system. The control system of PLC program flow chart shown in figure 2. 


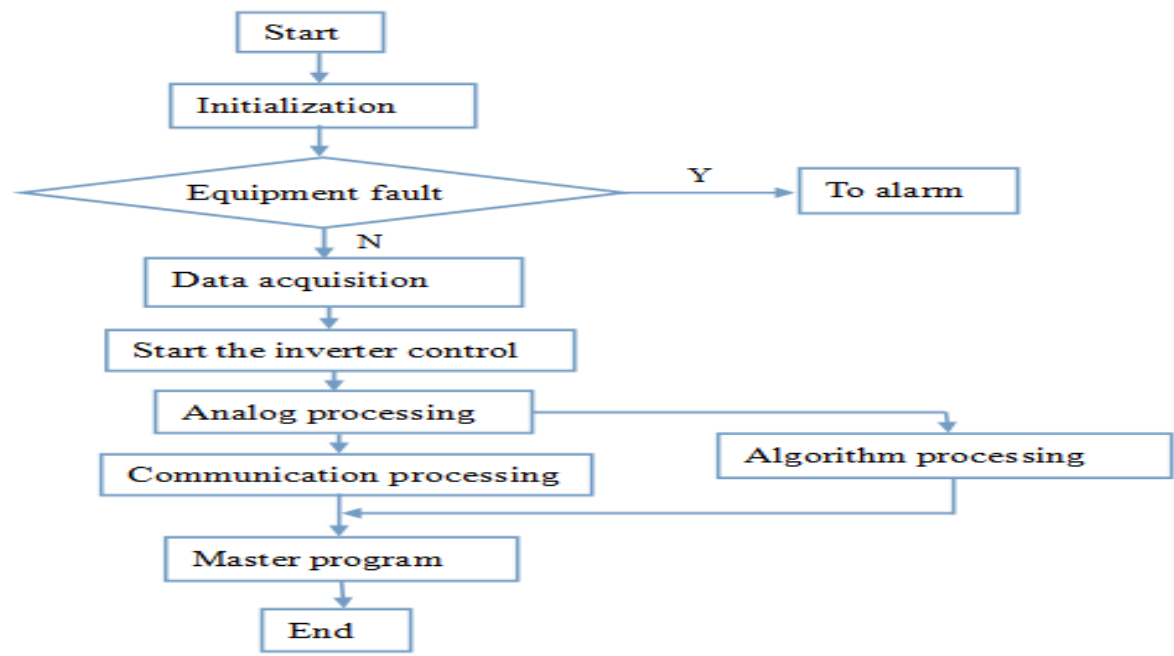

Figure 2: Sequential function chart of control system

\section{Application of WINCC configuration software}

On the system of process monitoring by WINCC configuration software Siemens company development with control system. It can faithfully reflect the various operation status and various operation parameters of field devices, still can use the graphical display of the alarm information change trend of operation data and intuitive form. Not only such, also can put the site control into the abstract principle diagram, and reflect the equipment status changes during the operation situation in the form of dynamic animation. This not only can provide control of clear thinking in system operation, and capable of operating at fault strikingly shows the problem, so as to improve the human-computer interaction when the work efficiency, reduce the system failure may bring losses. The control system of WINCC configuration screen structure diagram as shown in figure 3.

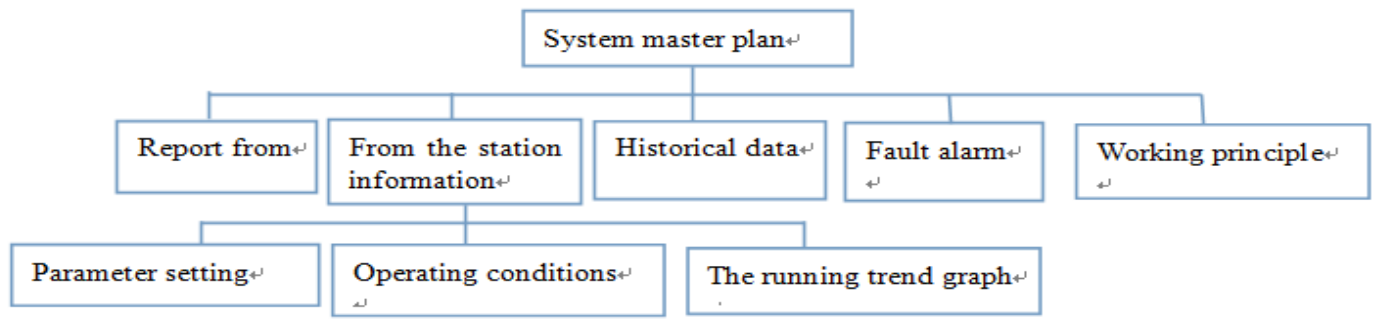

Figure 3: system structure diagram of the WINCC configuration screen

\section{Control system test}

The module test of PLC is mainly the input and output interface testing module includes a digital circuit, analog circuit interface and the interface between the module and communication is normal. First of all Q address bits are arranged one, to see if there is an output indicating lamp is bright, if the full light, showed that the module is normal. Open the state graph and then, and the I address switch commissioning manual switch, observe whether there is a "0" "1" changes, if changes to meet the switch input indicates normal input module. Touch screen and PLC connection is normal communication, mainly through the touch screen in judging whether the corresponding communication error occurred. Open the host computer system, firstly observe the communication is normal, and then observe the corresponding analog input and whether it meets the requirements.

\section{Conclusion}

The project control system using Siemens series S7-200PLC designed automatic control system of refrigeration unit. The system is running stable, good energy saving effect, high degree of automation. Reduce the labor intensity of the workers, give full play to the PLC operation speed, 
strong function, modify the program is convenient, less wiring, low failure rate, strong anti-jamming capability advantages and touch screen friendly man-machine interface function, achieved good results.

\section{References}

[1] Zhang Wentao. Siemens S7-200PLC application technology[M]. Beijing: Beijing University of Aeronautics and Astronautics Press, 2010

[2] Wang Yonghua. Modern electrical control and PLC application technology[M]. Beijing: Beijing University of Aeronautics and Astronautics Press, 2003

[3] Qiu Gongwei. PLC network communications and applications[M]. Beijing: Tsinghua University Press, 2000

[4] Xiang Xiaohan. Siemens PLC Advanced Applications Explained [M]. Beijing: Mechanical Industry Press, 2010

[5] Liang Mianxin, Luo Yanhong, Bian Chunyuan and so on. WINCC foundation and application development guide [M]. Beijing: Mechanical Industry Press, 2009 